International Journal of Linguistics, Literature and Translation (IJLLT)

ISSN: 2617-0299 (Online); ISSN: 2708-0099 (Print)

DOI: $10.32996 / \mathrm{ijllt}$

Website: https://al-kindipublisher.com/index.php/ijllt

\title{
Educational Radio Broadcasting During the Covid 19 Lockdown: Attitudes and Challenges Faculty of Arts and Humanities Sais-Fez Students as a Case Study \\ Dr. Sekkal Khadija \\ Associate Professor, English Department, Faculty of Arts and Humanities, Sais-Fez Sidi Mohamed Ben Abdellah University, Morocco \\ Corresponding Author: Dr. Sekkal Khadija, E-mail: sekkalkhadija2018@gmail.com
}

\section{ARTICLE INFORMATION}

Received: October 12, 2020

Accepted: November 07, 2020

Volume: 3

Issue: 11

DOI: 10.32996/ij|lt.2020.3.11.1

\section{KEYWORDS}

Covid 19, lockdown, educational radio broadcasting, English department students, attitudes, challenges

\section{ABSTRACT}

This paper sheds light on a primeval medium of distance learning, educational radio broadcasting. It explores the attitudes of English Department students of Faculty of Arts and Humanities, Sais-Fez, Morocco, and probes its impact on them knowing that the majority of these students idealize computers and the internet as natural, necessitous components of their lives. This paper also seeks to find out the challenges that students encounter using radio broadcasts in their learning during the Covid 19 lockdown. Based on an online-questionnaire administered to 158 students, the study shows that though university students have an inextricable relationship with technology, they hold favorable attitudes towards educational radio broadcasts aired on two radio stations of Fez, namely Radio SNRT and Radio Plus. The findings also reveal that students consider radio educational broadcasts as a learning aid, but not a real substitute for in-class education, that has an effective impact on students' learning during the Covid 19 lockdown. As for the challenges encountered by students, most of them are overcome as the audios are available on the faculty's platform, and students can replay them any time according to their time and pace of learning.

\section{Introduction}

After the first case of Coronavirus (Covid 19) appeared in Casablanca on March 2, 2020, Morocco has taken precautionary measures to safeguard citizens' health. One of these measures is the government's decision that all schools, universities, and other educational and vocational training institutions be closed on March 16, 2020. Accordingly, in-class/traditional learning has been substituted by distance learning/education, a method of teaching in which students along with their teachers are physically separated by geography and time (Kentnor, 2015, p. 22). For about a century, distance education has tremendously evolved in tandem with the advancement of telecommunications and information technologies, namely radio, television, computer, and the internet. Despite the diversity of distance learning tools and technologies, researchers have concurred that each medium, be it traditional or new, has never supplanted the other as every medium has found its own niche (Passerini \& Granger, 2000; Olumorin, Aderoju \& Ochay, 2018).

Distance learning dated back to 1728, in which Caleb Phillips, a university teacher, taught short-hand by correspondence (Battenberg, 1971; Holmberg, 1977). This form of distance education proved to be successful as people who were corresponded were perfectly instructed as those attending the class (Holmberg 2008). In the same line of argumentation, various studies have stipulated that there are no significant differences between distance education and in-class learning as per students' level of knowledge and learning outcomes (Schramm, 1962; Alghazo, 2005; Stack 2015). Some studies have even highlighted that the results of distance learners outdo those of traditional learners (Shachar and Neumann, 2003; Lapsley, Kulik, Moody \& Arbaugh, 2008).

\footnotetext{
K C AL-KINDI CENTER $\mathbf{R}$ D FOR RESEARCHA ANA Your gateway to world-doss research
}

Published by Al-KindiCenter for Research and Development. Copyright (c) the author(s). This is an open access article under CC BY license (https://creativecommons.org/licenses/by/4.0/) 
The present study probes educational radio broadcasting, a pioneer of educational technology, as a configuration of distance learning. It explores the question whether educational radio broadcasts, during the Covid 19 lockdown, are, in actual fact, a strong instructional tool positively influencing tertiary students given that the latter are, to a greater extent, centennials and millennials, described by Prensky (2001) as "digital natives". Put differently, this paper scrutinizes the impact of radio lessons, as a primeval medium, on university students idealizing computers and the internet as natural, necessitous components of their lives. It aims at determining the attitudes of English department students of Faculty of Arts and Humanities Sais-Fez towards the educational radio lessons aired on two local radio stations of Fez. It also examines the challenges that militate against students' listening to and understanding audio lessons. All in all, it is an assessment of the appropriateness and effectiveness of radio lessons in an attempt to find adapted, well-founded solutions to students' hindrances pertinent to using and understanding educational radio broadcasts. Subsequently, his study is set out to answer the following questions:

1- Are students motivated to listen to educational radio broadcasts?

2- Does educational radio broadcasting affect their learning positively?

3- Do students hold positive attitudes towards this form of learning, though it is not new if compared with the internet?

4- What are the challenges that students encounter deploying educational radio courses?

Many studies have accentuated the importance of educational radio broadcasting as a distance learning tool for tertiary education (Berman, 2008; Olakulehin, 2016; Sarmah \& Lama, 2017). In fact, this method was used by Sidi Mohamed Ben Abdellah University, Faculty of Arts and Humanities Sais Fez for the first time during the Covid 19 crisis. For this reason, this paper tries to assess the experience of students as per this distance learning tool.

\section{Review of the Literature}

Besides playing an important role in informing, entertaining and instructing the public (Nwaerondu, 1994; Hugellus, Adams, \& Romo-Murphy 2019), radio is deployed around the globe as an effective educational tool for formal education (Sweeney \& Parlato, 1982; Nwaerondu \& Thompson, 1987; Das, 2003). It was very popular as an educational medium during the early twentieth century before the emergence of the internet and other educational mediums based on advanced technology (Sarmah \& Lama, 2017). It was taken up first in the United States in 1922. Three universities, namely the Salt Lake, Wisconsin and Minnesota, were the pioneers to use the radio to broadcast courses (Farenga \& Ness, 2015). Then, educational broadcasting grew in other countries, including the United Kingdom in1924, Canada in 1925, Japan in 1933, India in1935, and Australia in 1948. By the 1930's radio was regarded as "the medium that would revolutionize education (Reiser 2001, p. 56) since it immensely boosted the field of distance learning. It offered programs based on school curriculum to supplement and improve the existing educational programs tutored in schools and universities (Bagley, 1930; Ackerman, 1945). Between 1950 's and 80's, radio broadcasting served throughout the world as an important distance education medium. At that time, it was a valuable resource for teaching and studying languages and social sciences at all levels of education (Garfinkel, 1972; Burnell, 1973).

Educational/instructional radio or educational/instructional broadcast is "the term given to the medium's use in formal learning systems, whether primary or higher education"(Berman, 2008, p. 2). It is a one-way transmission of course material distinguished by the absence of technical constraints. It overcomes the impediment of space to reach a wider audience and, consequently, does not disregard rural and isolated people of having the advantage of learning outside the classroom (Guarrera, 1972; Jamison \& Mcanany, 1978; Berman, 2008). Thanks to its immediacy, it "remains a viable medium that has proven educational worth in terms of both pedagogical importance and geographical reach" (Hammond, Asemanyi, OkaeAnti, \& Wornyo, 2016, p. 16) as it brings ready-made lessons to students living in remote regions. Besides annihilating distance, radio broadcasting is economical with low or no educational costs (Chandar \& Sharma, 2003).It improves access to different educational inputs and to a large population previously separated by geography and/or income. Ostensibly removing all feelings of distance, educational radio stands as an important distance education medium that, in a single broadcast, reaches hundreds of miles and therefore serves residents of rural areas and students from low-income families.

From the outset of its emergence, educational radio broadcasting has great potential in directing students to fully understanding their courses as many studies have revealed the positive impact of radio broadcasts on the performance and achievement of distance learning students. Sarmah \& Lama (2017) confirms that educational radio is enormously crucial for both developed and developing countries in the field of education, with special emphasis on its primordial role reflected in students' achievement in a variety of developing countries in Africa and Asia. Hammond, Asemanyi, Okae-Anti, \& Wornyo 2 
(2016) maintain that radio lectures enhance learning and provide information on various issues critical for students. For them, educational radio remains an effective way of complementing what is tutored in face to face, in-class lectures. In the same vein, Olakulehin (2016) points out that the use of instructional radio along with lectures enhances effective teachinglearning process; accordingly, he encourages lecturers to deploy it in tertiary education programmes. Burnell (1973) talks about the great potential that educational radio has in teaching foreign languages and social sciences as well as the great impact it has on students since it directs them to problem-solving techniques in attempting to fathom complex ideas. Odera $(2008,2011)$ likewise postulates that radio broadcasts help create a more solid, thriving learning environment as they encourage active engagement of students and motivate them for their progress). She also stresses the role of educational broadcasting in developing confidence to communicate effectively in English.

Though it has some drawbacks including lack of interaction between teachers and students, unavailability of feedback, and students' lack of control over the lesson pace, educational radio is "devoid of visual distractions which require students to engage both the eyes and ears attentively within a particular instructional period" (Hammond, Asemanyi, Okae-Anti, \& Wornyo, 2016, p. 23). It is traditional and often downgraded by other educational technology mediums, namely television and the internet; however, it has survived as a useful distance education medium that aids students to receive educational programming based and/or expanded on their classroom learning. In a nutshell, radio is, as pointed out by Todorova (2015, P. 53), "an old and 'dusty' technology, but it is a powerful, accessible, and affordable tool to teach students".

In Morocco, educational radio broadcasting started in the mid of 1960 's for primary level. Then, it has been progressively extended to other levels including tertiary education. During the Covid 19 curfew, Sidi Mohamed Ben Abdellah University (USMBA) Fez, Morocco, resorted to educational radio broadcasting as a distance learning medium to deliver courses to 89650 students belonging to various USMBA colleges. The university opted for this medium to reach remote, rural areas to avoid any possible digital divide that might be triggered off by other educational technology mediums such as the internet. Subsequently, USMBA banked on two regional radio stations: Radio SNRT and Radio Plus. Five different faculties, including Faculty of Arts and Humanities, Sais-Fez, belonging to USMBA benefited from 172 hours of broadcasting on the two regional stations with 112 hours of broadcasting on Radio SNRT, and 60 hours of broadcasting on Radio Plus starting from April 6 to May 22, 2020. The courses were aired on Radio SNRT every day for 2 hours from 2 to $4 \mathrm{pm}$. and replayed from 6 to 8 pm.. They were also aired on Radio Plus from 2 to $4 \mathrm{pm}$. and replayed from 9 to $11 \mathrm{pm}$. from Monday to Friday. In the last two weeks of broadcasting, Radio SNRT accentuated the broadcasting from two hours to four hours.

According to the minutes of a pedagogical meeting held on May 8, 2020 at Faculty of Arts and Humanities Sais-Fez, the faculty received 236 audios from different professors belonging to different departments. Actually, English department students belonging to the faculty benefited from 60 audio lessons stratified as follows: 36 audios directed to Semester 2 students, 10 audios to Semester 4 students, and 14 audios to Semester 6 students. These audios were posted at the faculty's platform, but not all of them were aired, only 34 audios, on Fez radio stations as different departments of the faculty benefited from 90 course lessons broadcast on both stations.

\section{Methodology}

The present study made use of descriptive survey design including both qualitative and quantitative analysis. The survey was selected as an appropriate method to collect data related to the problem under investigation. Data were collected via questionnaires, and the participants belonged to the Department of English of Faculty of Arts and Humanities Sais-Fez.

\subsection{Population and Sample}

The population for this study was made up of English Department students of Faculty of Arts and Humanities, Sais-Fez. However, only a sample size of 158 students was received as the majority of them had network connection problems or without network coverage at all. Other students did not have smart phones or laptops to access the Faculty's platform on which the questionnaire was posted.

The respondents were 90 females and 68 males. Composition of respondents with regard to age was as follows: 46 students were under the age of 21, 92 students were between 21 and 26, 16 students were aged between 27 and 36, and only 4 students were older than 36 . As per to their academic level, 32 students belonged to Semester 2, 40 students to Semester 4, and 86 students to Semester 6 . 


\subsection{The Questionnaire}

An online questionnaire was deployed as an instrument for the study to gather as many responses as possible from a reasonably large number of students belonging to Sais Faculty English Department. Apart from the basic demographic information about participants' gender, age and academic level, the questionnaire included nine questions.

Questions 1 and 2 were yes/no questions. Questions 3 and 5 were multiple choice-questions in which the 'other' option was added. Questions 4 and 6 were Likert scale questions. Ultimately, Questions 7, 8 and 9 were open-ended questions. Hence, these nine questions of the questionnaire generally ranged from closed-ended questions to obtain quantitative data to openended questions to obtain qualitative data.

All the respondents were asked to answer Questions 1 and 2. Question 3 was required to be answered only by the students who did not/could not listen to radio broadcasts. However, only the respondents who had succeeded to listen to audio lessons via radio were asked to answer questions $4,5,6,7,8$, and 9 .

\section{Data Analysis and Discussion}

Data collected were analyzed by using descriptive statistics. This included the use of frequency counts, percentages, and graphs.

1. With the Covid 19 lockdown, Semester 2, Semester 4 and Semester 6 radio lessons of different courses are being broadcast on the local radio station of Fez, are you aware that they are aired?

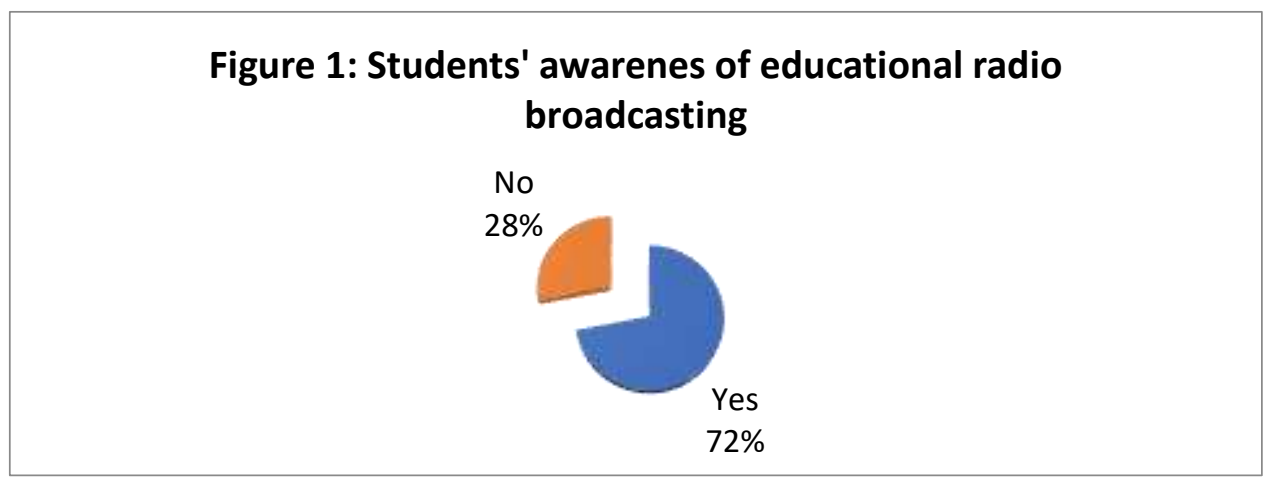

Figure 1 shows that the majority of students were aware of the educational radio broadcasting aired on the two radio stations of Fez with the average of $72 \%$. Yet, only $28 \%$ of the respondents did not have any idea about it.

In fact, most students were in the know, which is a testimony that USMBA, more specifically Faculty of Arts and Humanities, Sais-Fez, was instrumental in sensitizing students to tune in different courses. Proper sensitization made USMBA students up-to-date regarding their distance education mediums during the Covid 19 crisis.

\section{Do you listen to them via radio?}

Figure 2: Students' listening to audio lessons via radio

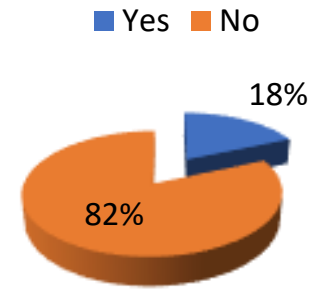


As revealed in Figure 2, only $18 \%$ of the respondents listened to audio lessons via radio. However, $82 \%$ did not. This shows that though students were aware of educational broadcasts, the majority did not use radio as a distance learning medium.

The respondents who did not succeed to listen to audio lessons via their receiving sets were required to answer the next question to find out the obstacles that militated against their listening.

3. If not, what are the obstacles that impede against your listening to the radio lessons? The technical problem of inadequate power, inappropriate time of airing radio lessons, the insignificance of radio lessons to listen to, the availability of radio lesso ns at the distance learning platform of the faculty, or 'other'.

\section{Figure 3: Students' obstacles to listen to radio lessons}

The technical problem of inadequate power supply

Inappropriate time of airing radio lessons

The insignificance of radio lessons to listen to

\section{$3.30 \%$}

The availability of radio lessons at the distance learning platform of the faculty

Figure 3 shows the obstacles that impeded against students' listening to radio broadcasts. $34 \%$ of the respondents indicated that 'the technical problem of inadequate power supply' was the most prominent problem. Closely followed by $29 \%$ of the respondents who stated that the availability of the same audio lessons aired on Fez radio stations at the faculty's distance learning platform was one of the reasons why they did not draw upon their radio sets. $15.90 \%$ acknowledged that the timing of airing educational broadcasts did not suit them. Yet, only $3.30 \%$ expressed their lack of interest in educational radio broadcasts.

Further obstacles expressed by respondents were related to receiving sets. While some respondents declared that they did not own radio sets, others assumed that theirs (or their parents') were decrepit and unserviceable.

Accordingly, the challenges students encountered were mainly technical. They were connected to reception problems including weak signal, interfering signal and students' failure to find the exact radio station frequency. For the respondents (15.90\%) who claimed that the airing time was inconvenient, they might not be aware that those who missed the broadcasts could listen to them replayed during weekdays on Radio SNRT and Radio Plus. In so doing, USMBA aimed to ensure that all students access to diverse audios at different times of the day.

The availability of radio lessons on the faculty's platform was a hurdle and a solution at the same time: a hurdle as it made students not eager enough to follow directly their lessons via radio and a solution as they could listen to what they had missed according to their learning time and pace. On the whole, a large majority of students, either those who could tune in these audios or those who could not, showed their positive attitudes towards radio broadcasts as only $3.30 \%$ revealed their unconcern about these broadcasts. 


\section{How often have you encountered problems in understanding lessons via radio broadcasts? Always, very frequently,} occasionally, rarely, very rarely, or never.

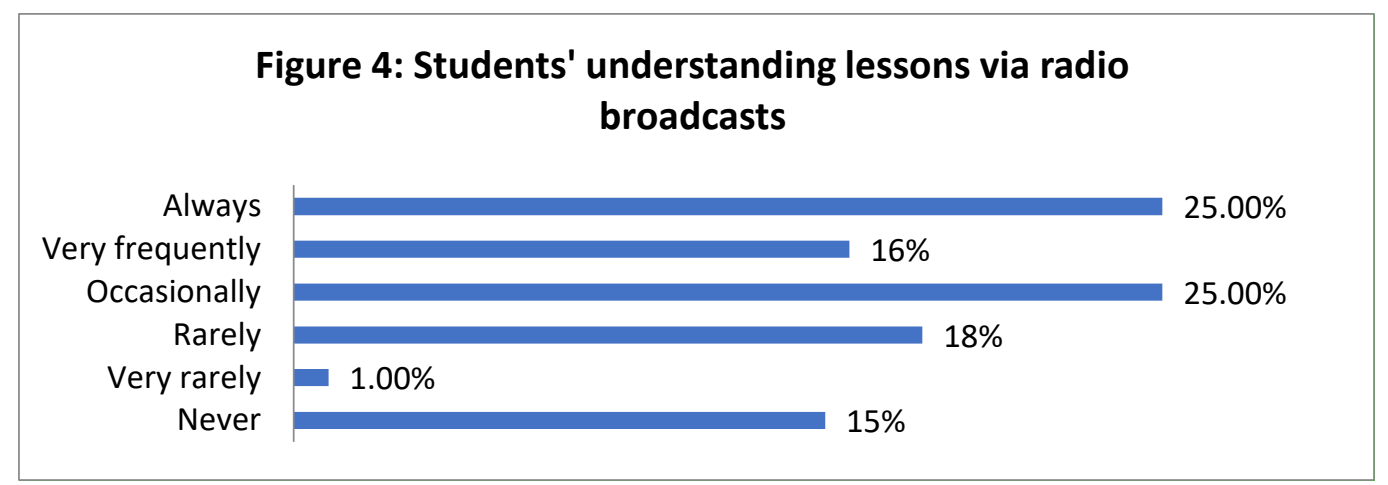

Figure 4 indicates how often students encountered problems in understanding lessons via broadcasting. The majority of the respondents claimed that they, to a certain extent, suffered from problems of comprehension. $25 \%$ stated 'always, $16 \%$ 'very frequently' and $25 \%$ 'occasionally'. $18 \%$ and $1 \%$ of the respondents respectively declared that they 'rarely' and 'very rarely' faced problems regarding intelligibility. Yet, $15 \%$ of the respondents revealed that they could understand the audios without any problem. To understand the source of their unintelligibility, students were asked about the nature of the problems they encountered.

\section{Are the problems encountered related to the content of audios, unfamiliar vocabulary, little control over the pace of} delivery, or other?

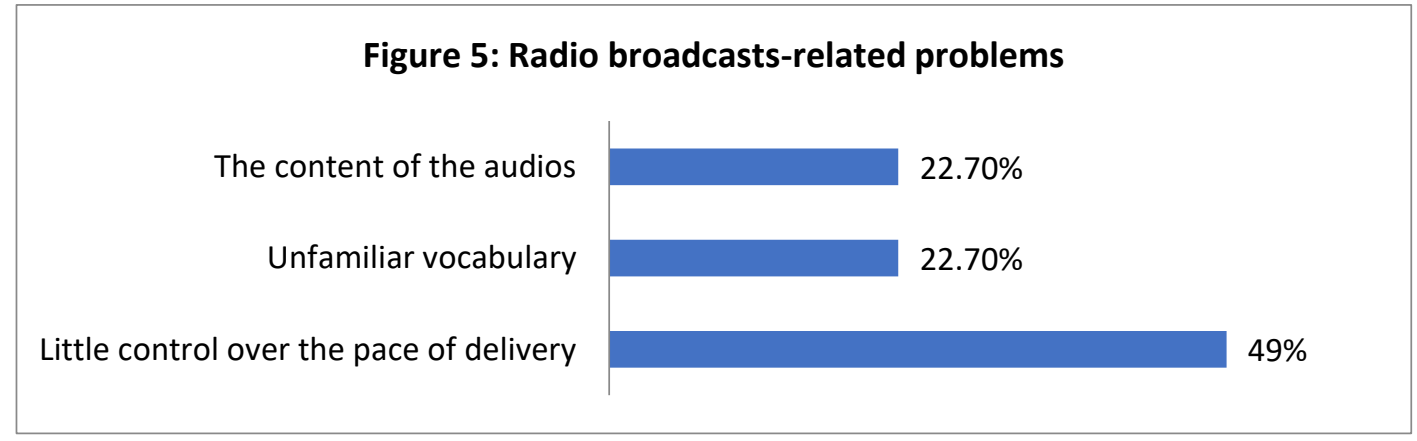

Figure 5 illustrates the nature of the problems encountered by students. Approximately half of the students (49\%) claimed that the main source of their unintelligibility was that they had little control over the pace of delivery. $22.7 \%$ found difficulty in understanding the content of audios, and a similar rate (22.7\%) encountered vocabulary problems. In the 'other 'option, some respondents expressed that the lack of interaction between professors and students, the length of the audios, especially those exceeding 20 minutes, and the sound quality of some audios impacted their comprehension.

The biggest problem with understanding radio lessons was that respondents were not able to control how quickly some professors delivered their audios. The majority of students could not follow the audios to copiously concentrate and take notes. The second problem was 'unfamiliar vocabulary' that students faced. This problem made them miss the meaning of some sentences or a part of the audio, especially when they could not guess the meaning of some key words. 'The content of the audios' was also a problem, especially for the students who had no prior idea about their courses. To overcome these obstacles, students should have an idea about their courses and study specific-related terms (jargon) of each course. In fact, this could be realized by reading booklets of different courses available at the Photocopy Center of the faculty before the lockdown. After the lockdown, they were posted on the faculty's distance learning platform weeks before the airing of radio lessons.

Students also mentioned lack of interaction as an obstacle to their intelligibility. In fact, the audios were one-way and no feedback and/or questions could be provided or asked. In this context, interactive radio broadcasts could be considered as a distance learning solution as they emphasize interactivity. Opposed to conventional educational radio broadcasting, interactive radio broadcasts require professors to react verbally to questions asked by students. Moreover, audios should not 
exceed 15 or at most 20 minutes to ensure that all students could concentrate on the content of the broadcasts. The quality of sound was also a problem that students suffered from. Due to the Covid 19 lockdown, many professors were compelled to record courses at home, mostly with their cell phones, which resulted in the fact that some of the audios were not of a high sound quality.

6. Based on your experience, are educational radio broadcasts in learning during the Covid 19 lockdown very important, important, moderately important, slightly important, or unimportant?

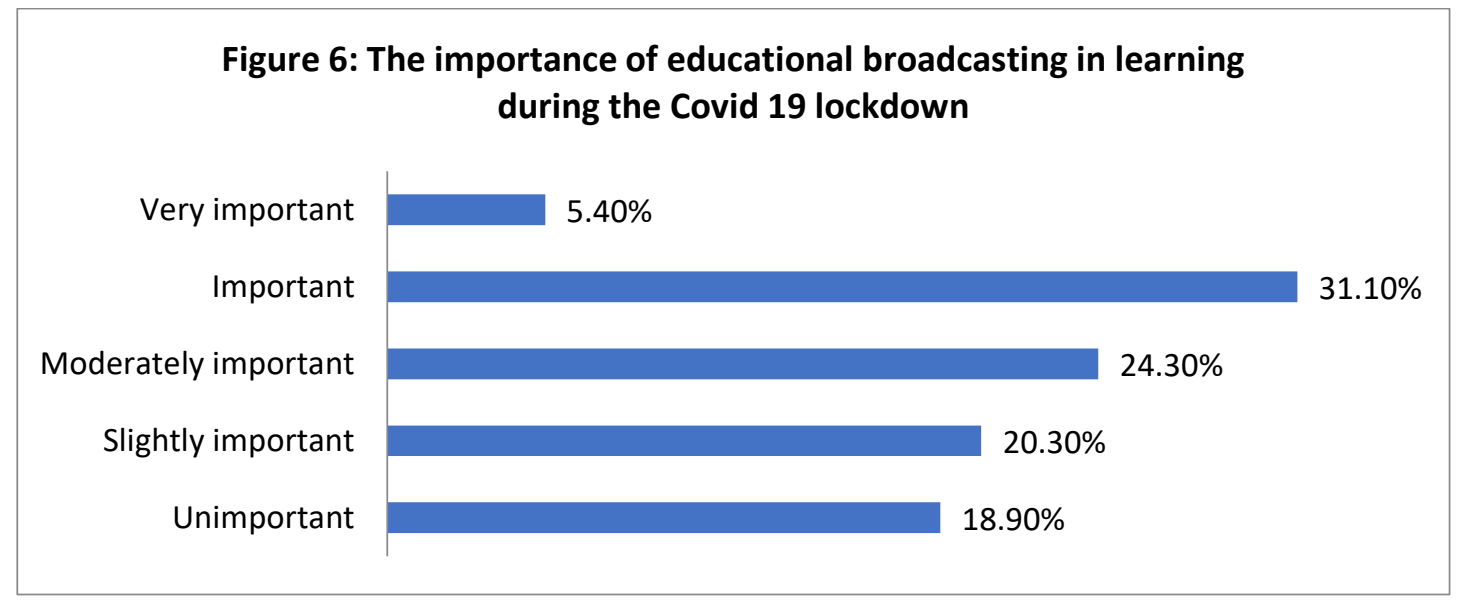

As revealed in Figure 6, the majority of the respondents acknowledged the importance of instructional radio broadcasting during Covid 19 crisis. $5.40 \%$ of the respondents claimed that it was 'very important', $31.10 \%$ affirmed that it was 'important', $24.30 \%$ indicated that it was 'moderately important'. However, $20.30 \%$ stated that it was 'slightly important', and only $5.40 \%$ were convinced that it was 'unimportant'.

The majority of the respondents admitted the importance of radio lessons. In fact, these lessons ought to be considered a means to boost students' listening competencies as they motivate them to deeply understand the gist of the lesson depending on their listening skills only, without getting any visual support such as non-verbal cues. Furthermore, thanks to these audios, students develop autonomous learning, promote thinking as well as problem-solving skills.

7. Could these radio broadcasting lessons always, often, sometimes, rarely, or never be a substitute for in-class lessons?, why?

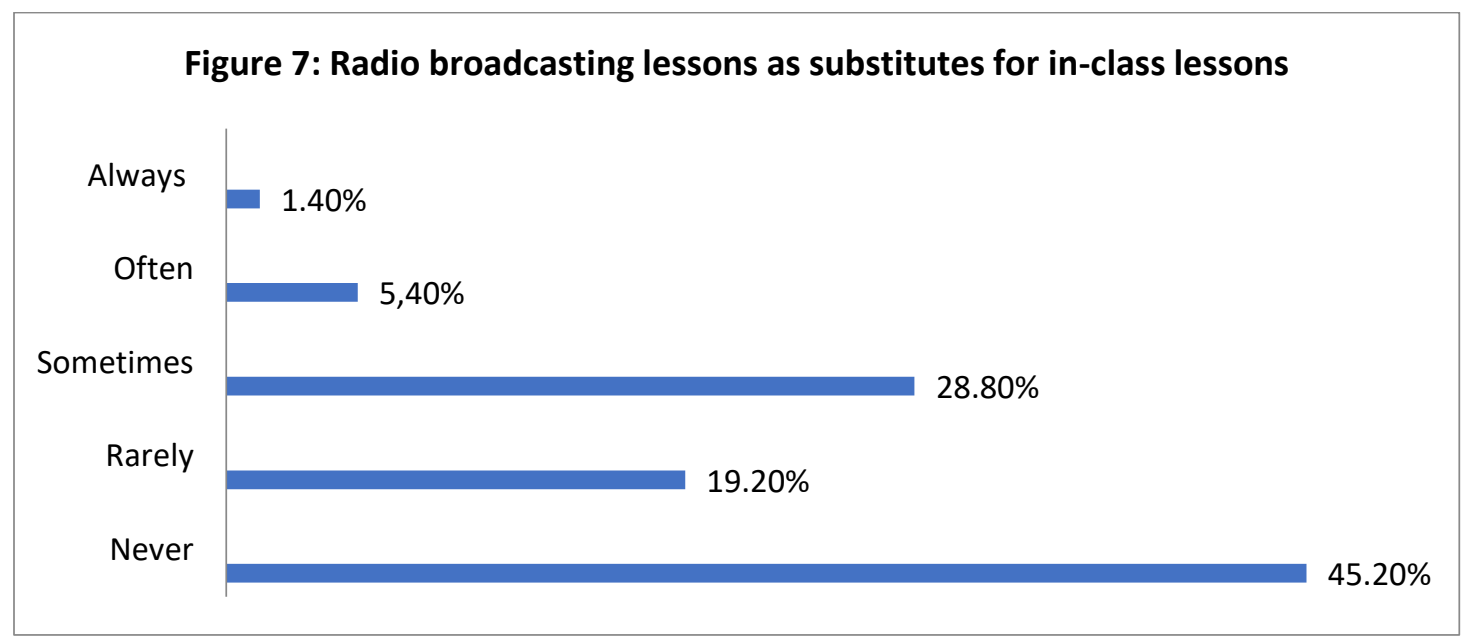

Figure 7 shows whether radio broadcasts could substitute in-class lessons or not. Approximately, half of the respondents (45.2\%) pointed out that in-class lessons could never be substituted by educational radio lessons. $19.20 \%$ acknowledged that they could rarely substitute them, $28.80 \%$ asserted that sometimes they could be a substitute. $5.40 \%$ of the respondents 
admitted that they could often be a substitute. However, only $1.40 \%$ said that radio broadcasting always offset in-class lessons.

Many respondents stated that in-class lessons generally could not be compensated by radio broadcasts. They maintained that being in contact with professors and classmates motivated them to participate, discuss and ask questions to get a full understanding of the lesson. Others regarded educational radio broadcasting as a generally boring way of learning lacking face-to face interaction. This finding underlines that this mode of instruction could not offset in-class, face to-face learning.

8. Have audio lessons helped you with learning during lockdown? Always, often, sometimes, rarely, or never, say why?

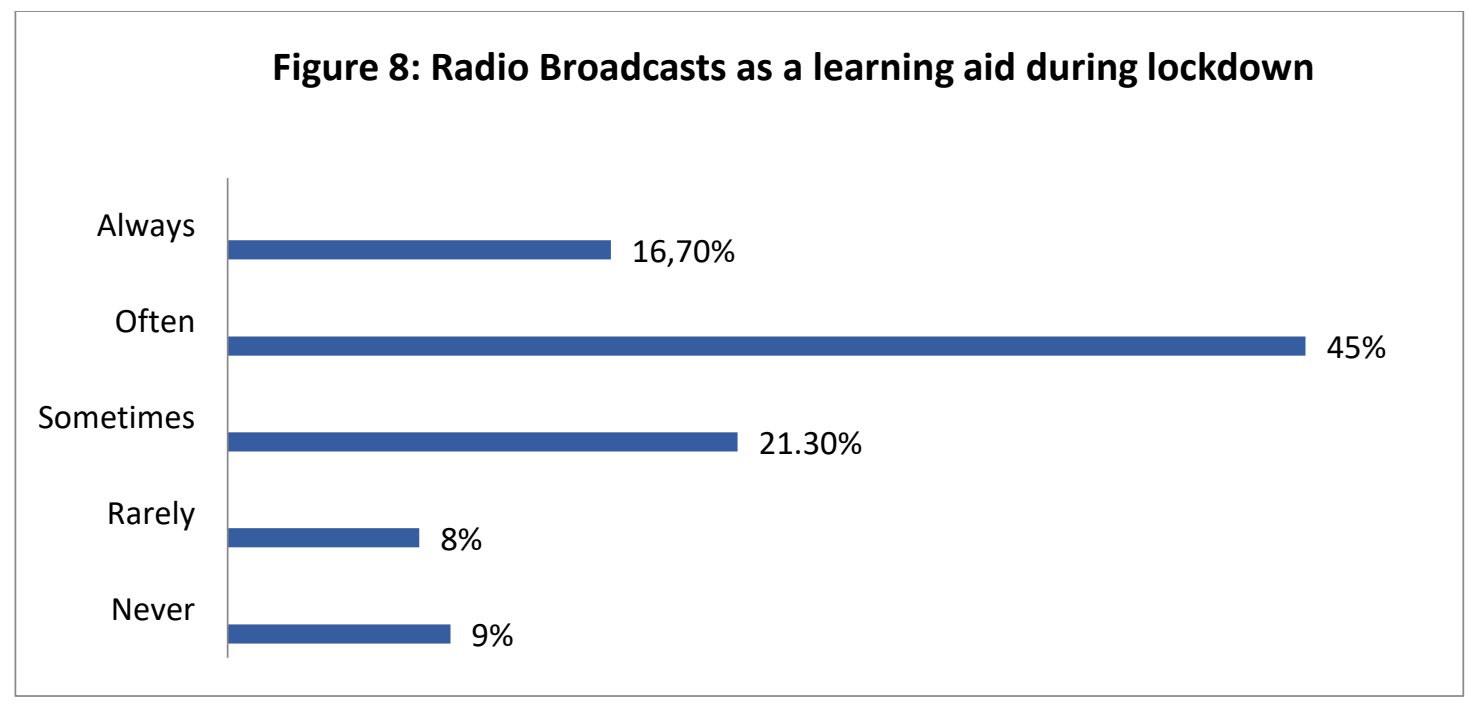

As shown in Figure 8, the majority of the respondents stated that radio lessons helped them in a way or another with learning during lockdown. $16.70 \%$ claimed that they 'always' helped them, 45\% 'often', $21.30 \%$ 'sometimes' and $8 \%$ 'rarely'. Yet, 9\% affirmed that they were not of any help at all.

Many respondents affirmed that audio lessons supported them since they complemented the online course booklets. Some of them stated that oftentimes they encompassed more details, and they were shorter and more concise than online booklets. For the students who considered radio lessons as not a source of help, they regarded online booklets sufficient as they were more comprehensive. On the whole, instructional radio broadcasting was admitted to be a learning aid during the Covid 19 crisis.

\section{To what extent have you benefited from these radio lessons? Very much, rather much, to some extent, only a little,} or not at all, say why?

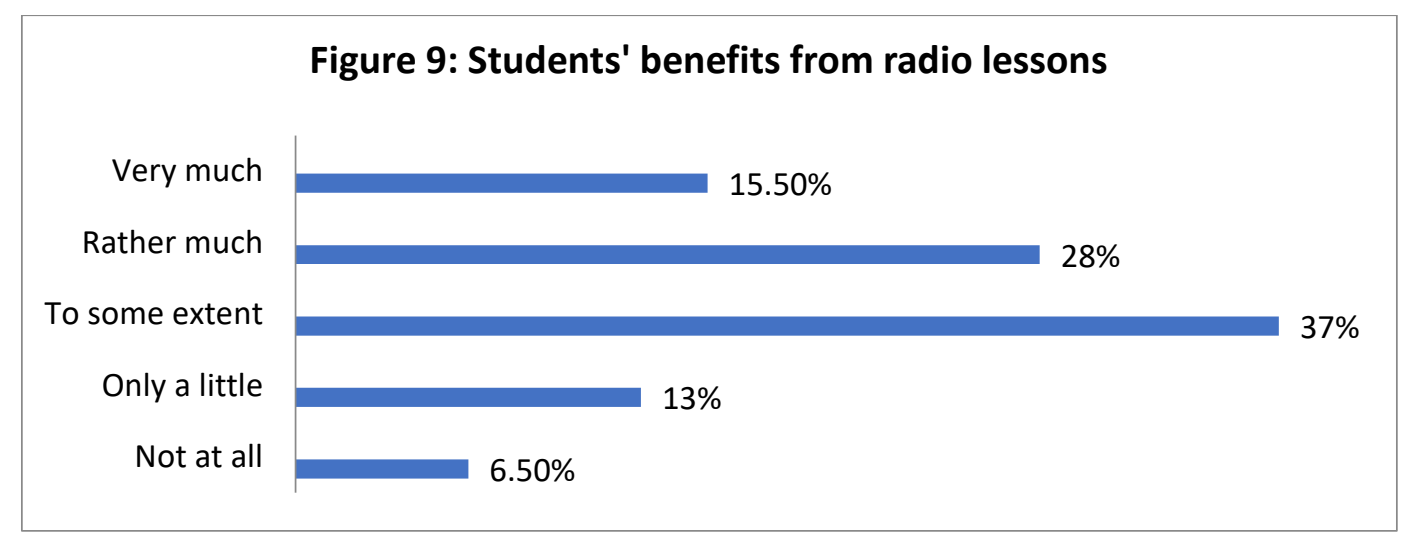

The majority of the respondents, as illustrated in Figure 9, declared that they benefited from radio courses. $15.5 \%$ of them benefited 'very much', 28\% 'rather much', and 37\% 'to some extent'. Yet, $13 \%$ of the respondents revealed that they benefited 'only a little' and ultimately $6.5 \%$ stated that they did not benefit at all. 
A large majority of students considered radio broadcasts as simplified versions of online booklets. They claimed that these broadcasts even contained some extra information about different courses. Some respondents affirmed that, thanks to these audios, they honed their listening skills and corrected some of their constant mispronunciation. In fact, though some students found difficulties fathoming the content of some audios as reflected in Figure 4, they proclaimed that radio broadcasts were of help during the Covid 19 crisis.

All in all, besides being a means of instruction, educational radio broadcasting helped students become autodidactic and selfregulated learners as they tried to customize with the lesson pace of different audios delivered by different professors. For this reason, it is recommended that Moroccan universities incorporate radio lessons, in a better way, interactive radio broadcasting, in teaching and learning along with lectures. For this reason, a national educational radio broadcast should be set up to include different courses of different universities so that students can thoroughly benefit from this tool of learning.

\section{Conclusion}

Being an assessment of the effectiveness of radio lessons during the Covid 19 lockdown, study reveals that students have demonstrated favorable attitudes towards educational radio broadcasts aired on two radio stations of Fez, namely Radio SNRT and Radio Plus. A large majority of Sais Faculty English Department students are millennials and centennials whose relationship with technology is inextricable. However, they approve of radio lessons by and large described as an outdated configuration of distance learning. Students consider radio educational broadcasts as a learning aid, but not an actual substitute for in-class education, that has an effective impact on students' learning during the Covid 19 lockdown. Though students sometimes faced problems in understanding the audios, they show their motivation towards this medium of distance learning.

With the introduction of instructional radio broadcasts as a new method for students during this crisis, it is evident that they would face difficulties to listen to and understand radio lessons. The challenges students encountered are twofold, technical and contentual. But, generally, these obstacles are overcome as the audios are available on the faculty's platform, and students can replay them any time according to their time and pace of learning.

It is note-worthy to mention that many students couldn't answer the questionnaire posted online at the faculty's platform as a large number of them live in remote and rural areas lacking reliable internet access or devices during the period of lockdown. Many of these students have benefited intensively from educational radio broadcasting which is a learning solution that does not serve to widen digital divide. Therefore, during these circumstances of lockdown, audio lessons are an added value which aids students in their learning process. This study has the limitation of the number of the students investigated. In fact, more respondents could enrich the data and the findings of the study. However, since the questionnaire was online, many students, especially those in remote regions, could not have access to it as they had network connection problems. Subsequently, further studies are needed to shed more light on this topic, with more emphasis on teachers' attitudes towards educational radio broadcasting.

\section{References}

[1] Ackerman, W. C. (1945). The dimensions of American broadcasting. The Public Opinion Quarterly, 9(1), 1-18.

[2] Alghazo, A. (2005).C omparing Effectiveness of Online and Traditional Teaching Using Students' Final Grades. Online Journal for Workforce Education and Development OJWED, 1(3): 1-11. Retrieved on: October 12, 2012 from: http://opensiuc.lib.siu.edu/cgi/viewcontent.

[3] Bagley, W. C. (1930). Radio in the Schools. The Elementary School Journal, 31(4), 256-258.

[4] Battenberg, R. W. (1971). The Boston Gazette, March 20, 1728. Epistolodidaktika, 1, 44-45.

[5] Berman, S.D. (2008). The return of educational radio? The International Review of Research in Open and Distributed Learning, 9(2), (n.p.). Retrieved from : http://www.irrodl.org/index.php/irrodl/article/view/563/1038.

[6] Burnell, J. B. (1971). How shortwave radios can improve teaching effectiveness. Educational Technology (Teacher and Technology Supplement), 11 (10), 60-61.

[7] Chandar, U. \& Sharma, R. (2003). Bridges to effective learning through radio. The International Review of Research in Open and Distance Learning, 4(1). Retrieved from : http://www.irrodl.org/index.php/irrodl/article/view/118.

[8] Das, J.K (2003). Educational Broadcast through Radio. Retrieved from : http//www.aiaer/net/ejournal/Vol19107/8.htm.

[9] Farenga, S.J. and Ness, D. (Eds.) (2005). Encyclopedia of Education and Human Development (Volume I). New York: M.E. Sharpe, Inc.

[10] Garfinkel, A. (1972). Teaching Languages via Radio: A Review of Resources. The Modern Language Journal, 56 (3), 158-162. Retrieved from: https://www.jstor.org/stable/324038?seq=3\#metadata_info_tab_contents.

[11] Guarrera, S. (1972). Active Participation of Italian Pupils in School Radio Programmes. European Broadcasting Union Review, $23,10-14$. 
[12] Hammond, C., Asemanyi, A.A., Okae-Anti, A. and A.A. Wornyo. (2016). Teaching and Learning Communication Skills Through Radio Lecture Series: Challenges and Prospects. New Media and Mass Communication, 55. Retrieved from : https://iiste.org/Journals/index.php/NMMC/article/viewFile/34381/35352.

[13] Holmberg, B. (1977). Distance Education: A Survey and Bibliography. London: Kogan Page.

[14] Hugellus, K., Adams, M., \& Romo-Murphy, E. (2019). The Power of Radio to Promote Health and Resilience in Natural Disasters: A Review. Int J Environ Res Public Health, 16(14): 2526. Retrieved from : https://www.mdpi.com/1660-4601/16/14/2526/htm.

[15] Jamison, D., \& McAnany, E. (1978). Radio for education and development. California: Beverly-Hills.

[16] Kentnor, H. (2015). Distance education and the evolution of online learning in the United States.

a. Curriculum and Teaching Dialogue, 17(1-2), 21-34.

[17] Lapsley, R., Kulik, B., Moody, R., \& Arbaugh, J. B. (2008). Is Identical Really Identical? An Investigation of Equivalency Theory and Online Learning. Journal of Educators Online, 5 (1). Retrieved from http://www.thejeo.com/

[18] Nwaerondu, N. G. (1994). Educational radio: A tool for rural change. Retrieved October 17, 2009, from http://www.eric.ed.gov/ERICWebPortal/contentdelivery/servlet/ERICServlet?accno=ED390624.

[19] Nwaerondu, N.G. \& Thompson, G. (1987). The use of educational radio in developing countries: Lessons from the past. International Journal of E-learning \& Distance Education, 2 (2), 43-54. Retrieved from : http://www.ijede.ca/index.php/jde/article/view/315/209.

[20] Odera, F. Y. (2008). Learning Kiswahili language by radio at distance in secondary schools in Nyakach. Nyando district. Kenya. Malaysian Journal of Distance Education, 9(2), 89-105.

[21] Odera, F. Y., \& Kisumu, K. (2011). Learning English language by radio in primary schools in Kenya. US-China Education Review A, 7.

[22] Olakulehin, F.K. (2016). Impact of Instructional Radio Delivery Mode on Academic Achievement of Distance Learning Students' in Computer Science. US-China Education Review B, 6 (12), 688-698.

[23] Olumorin, C. H., Aderoju, M.A and A.O. Onojah. Students awareness and utilization of educational broadcasts to learn in Ogbomoso, Oyo State Nigeria. Turkish Online Journal of Distance Education, 19(3),182-192.

[24] Passerini, K. and M.J. Granger (2000). A developmental model for distance learning using the Internet. Computers and Education. 34(1), pp. 1-15.

[25] Prenksy, M. (2001). Digital natives, digital immigrants: Part 1. On the Horizon, 9(5), 1-6. https://doi.org/10.1108/10748120110424816

[26] Reiser, R.A. (2001). A History of Instructional Design and Technology: Part I: A History of Instructional Media. Educational Technology Research and Development, 49(1), 53-64.

[27] Sarmah, B. and S. Lama. (2017). Radio as an Educational Tool in Developing Countries: Its Evolution and Current Usages. International Conference on Developmental Interventions and Open Learning for Empowering and Transforming Society, Guwahati, Assam, India. Retreived from : https://www.researchgate.net/publication/322355675_Radio_as_an_Educational_Tool_in_Developing_C ountries_Its_Evolution_and_Current_Usages.

[28] Schramm, W. (1962). What we know about learning from instructional television. In Educational Television: The next ten years. Stanford CA: The Institute for Communication Research, Stanford University.

[29] Shachar, M., \& Neumann, Y. (2003). Differences between traditional and distance education academic performances: A meta-analytic approach. Retrieved from : http://www.agecon.ksu.edu/accc/kcdc/PDF Files/differences.pdf.

[30] Stack, S. (2015). Learning Outcomes in an online vs traditional course. International Journal for the Scholarship of Teaching and Learning, 9(10). Retrieved from :https://doi.org/10.20429/ijsotl.2015.090105

[31] Sweeney, W.O., \& Parlato, M.B. (1982). Using radio: for primary health care. Washington, D.C.: American Public Health Association.

[32] Todorova, M. (2015). Dusty but Mighty: Using Radio in the Critical Media Literacy Classroom. Journal of Media Literacy Education, 6(3), 45- 56. 